Hydrol. Earth Syst. Sci., 12, 293-301, 2008

www.hydrol-earth-syst-sci.net/12/293/2008/

(C) Author(s) 2008. This work is distributed under

the Creative Commons Attribution 3.0 License.

\title{
The olive tree: a paradigm for drought tolerance in Mediterranean climates
}

\author{
A. Sofo ${ }^{1}$, S. Manfreda ${ }^{2}$, M. Fiorentino ${ }^{2}$, B. Dichio ${ }^{1}$, and C. Xiloyannis ${ }^{1}$ \\ ${ }^{1}$ Dipartimento di Scienze dei Sistemi Colturali, Forestali e dell'Ambiente, Università degli Studi della Basilicata, Via \\ dell'Ateneo Lucano, 10, 85100 Potenza, Italy \\ ${ }^{2}$ Dipartimento di Ingegneria e Fisica dell'Ambiente, Università degli Studi della Basilicata, Via dell'Ateneo Lucano, 10, \\ 85100 Potenza, Italy
}

Received: 6 August 2007 - Published in Hydrol. Earth Syst. Sci. Discuss.: 6 September 2007

Revised: 10 January 2008 - Accepted: 25 January 2008 - Published: 27 February 2008

\begin{abstract}
Olive trees (Olea europaea L.) are commonly grown in the Mediterranean basin where prolonged droughts may occur during the vegetative period. This species has developed a series of physiological mechanisms, that can be observed in several plants of the Mediterranean macchia, to tolerate drought stress and grow under adverse climatic conditions. These mechanisms have been investigated through an experimental campaign carried out over both irrigated and drought-stressed plants in order to comprehend the plant response under stressed conditions and its ability to recover. Experimental results show that olive plants subjected to water deficit lower the water content and water potentials of their tissues, establishing a particularly high potential gradient between leaves and roots, and stop canopy growth but not photosynthetic activity and transpiration. This allows the continuous production of assimilates as well as their accumulation in the various plant parts, so creating a higher root/leaf ratio if compared to well-watered plants. Active and passive osmotic adjustment due to the accumulation of carbohydrates (in particular mannitol and glucose), proline and other osmolytes have key roles in maintaining cell turgor and leaf activities. At severe drought-stress levels, the non-stomatal component of photosynthesis is inhibited and a light-dependent inactivation of the photosystem II occurs. Finally, the activities of some antioxidant enzymes involved in the scavenging of activated oxygen species and in other biochemical pathways increase during a period of drought. The present paper provides an overview of the driving mechanisms adopted by olive trees to face drought stress with the aim of better understanding plant-soil interactions.
\end{abstract}

Correspondence to: S. Manfreda

(salvatore.manfreda@unibas.it)

\section{Introduction}

The Mediterranean-climate regions are characterised by a cycle of temperatures out of phase with the rainfall forcing, producing mild to cool rainy winters and dry summers. The hydrological variability of Mediterranean climate regions is due to a combination of rainfall (irregularly distributed in time and space) and heterogeneous land topography. The existing variety of climatic conditions in these areas is due to the specific configuration of land surface (topography) and distance from sea (Fiorentino et al., 2006). The climatic forcing of Mediterranean areas induces a temporal variability in the soil moisture dynamics that is strongly affected by seasonal fluctuations between humid and dry conditions (e.g., Teuling et al., 2005; Bolle, 2003). This behaviour is clearly due to the characteristic climatic conditions of the region that moves from rainy winters to dry summers characterised by low air humidity, high solar radiation and consequently high rates of evapotranspiration. In these periods, water becomes a limiting factor producing prolonged and intense drought stress in plants.

Mediterranean vegetation dealing with this peculiar soil moisture dynamics has developed a number of physiological mechanisms to tolerate drought stress and grow under adverse climatic conditions (Lo Gullo and Salleo, 1988). The olive tree (Olea europaea L.) is one of the most typical and economically important tree culture species belonging to the Mediterranean area. In fact, as for many Mediterranean species adapted to semi-arid climates (Lo Gullo and Salleo, 1988), the olive tree is able to tolerate the low availability of water in soil by means of morphological, physiological and biochemical adaptations acquired in response to periods of water shortage often lasting throughout the springsummer period (Connor and Fereres, 2005). In this species, a series of strategies act synergically against drought stress.

Published by Copernicus Publications on behalf of the European Geosciences Union. 
The most relevant mechanisms are the regulation of stomata closure and transpiration (Moreno et al., 1996; Nogués, and Baker, 2000), the regulation of gas exchange (Moriana et al., 2002), a very developed osmotic adjustment (Chartzoulakis et al., 1999), the regulation of the antioxidant system (Bacelar et al., 2007), the appearance of leaf anatomical alterations (Chartzoulakis et al., 1999), and the ability of extracting water from the soil due to a deep root system (Fernandez et al., 1997) and to a high water potential gradient between canopy and root system (Tombesi et al., 1986). Olive trees are confirmed to be efficient soil water users, thanks to their xylem sap transport and the ability to maintain significant rates of gas exchange even during drought stress (Tognetti et al., 2004). For these reasons, the olive tree can be defined as a model plant for drought tolerance in Mediterranean climates.

The olive is the emblematic tree of the Mediterranean regions and constitutes an integral and significant part of the Mediterranean environment and culture, however, its ecological importance has only recently been acknowledged (Loumou and Giourga, 2003). Olive growing is often confined to slopes or fairly ragged land and occupies important parts of mountains and hills (Favia and Celano, 2005) because its culture reduces soil erosion and favors the preservation of a high bio-diversity (Loumou and Giourga, 2003).

Understanding the mechanisms by which olive plants face drought stress under extreme environmental condition is essential for selecting more drought-tolerant cultivars and hence for saving water resources in semi-arid environments. The aim of the study is to analyze drought effects on physiological and biochemical mechanisms of olive plants, such as: gas exchange, photosynthetic efficiency, photoinhibition, osmotic adjustment, cell wall properties, antioxidant enzymes, markers of oxidative stress and growth parameters. Some of those processes have been monitored both under drought conditions and during the following rewatering phase in order to better explain the high degree of tolerance to water deficit observed in this species. The information here obtained may improve our knowledge regarding the temporal variability of plant-soil-atmosphere continuum in this typical species of Mediterranean semi-arid regions.

\section{Materials and methods}

Experimental results discussed in the present paper were collected from two experiments: the first carried out on plants grown in vase under controlled conditions and the second on plants grown in field conditions. The use of two experimental approaches is due to the wide spectrum of physiological parameters investigated herein. In the first case, it is possible to obtain a relatively large number of measures referred to plants under equal soil moisture conditions (or water stress), whereas the field experiment was used to avoid the limiting effect of vases in root growth. Consequently, the measurements of physiological and biochemical parameters were taken during the first experiment, while growth parameters of plants were recorded in the second one.

\subsection{Description of the first experiment}

The first experiment was carried out at Metaponto (Southern Italy, Basilicata Region - N $40^{\circ} 24^{\prime}$, E $\left.16^{\circ} 48^{\prime}\right)$ using approximately 60 own-rooted olive plants (Olea europaea L., cv. "Coratina") subjected to an induced water stress. Olive plants were grown uniformly outdoors in $0.016 \mathrm{~m}^{3}$ pots containing loamy sand ( $73.2 \%$ sand, $13.3 \%$ silt and $13.5 \%$ clay). Drought stress levels were defined on the basis of the values of leaf water potential $\left(\Psi_{w}\right)$ measured pre-dawn using a pressure chamber (PMS Instrument Co. Corvallis, OR, USA), according to Turner (1981). The effects of different levels of soil water deficit on gas exchange, photosynthetic efficiency, photoinhibition, osmotic adjustment, cell wall properties, antioxidant enzymes activity and markers of oxidative stress were studied.

Pots were covered with plastic film and aluminium foil in order to avoid evaporation from the soil surface and to minimize temperature increase inside the containers. All plants were weighed each evening in order to calculate the amount of water transpired. A limited number of plants were used as a non-stressed control maintaining the soil water content at about $85 \%$ of soil water holding capacity and providing, every evening, the amount of water lost through transpiration during the day. Drought-stressed olive plants were subjected to a drought period of 22 days applying a gradual and controlled water reduction for ten days and after which irrigation ceased. Once the maximum level of drought stress had been reached, all plants were rewatered to recreate optimal soil water conditions.

The measurements of gas exchange were carried out using the portable photosynthesis system LCA-4 (ADC, UK) operated at $200 \mu \mathrm{mol} \mathrm{m}^{-2} \mathrm{~s}^{-1}$ flow rate, under natural temperature, relative humidity and full sunlight conditions (at 09:0010:00). Chlorophyll- $a$ fluorescence from photosystem II was recorded at $650 \mathrm{~nm}$ by using the time-resolving portable fluorimeter (Plant Efficiency Analyser, PEA, Hansatech Instrument Ltd., UK).

In order to measure the degree of non-stomatal limitation to photosynthesis (photoinhibition), fluorescence relaxation curves were recorded at the beginning of drought treatment, at the end of the drought stress period and at the end of the rewatering period using the method of Walters and Horton (1991). Cell contents were extracted by squeezing leaf and root tissues in sterilized plastic syringes and the extract was used to determine osmolarity by an osmometer (Wescor model 2000, Logan, UT, USA) calibrated against a salt solution. Osmotic adjustment was calculated as reported by Girma and Krieg (1992) whereas elastic modulus was determined after Tyree and Jarvis (1982). Antioxidant enzymes and lipoxygenase were extracted and their activities were evaluated following the methods proposed by Sofo 
et al. (2004a). Finally, proline and malondialdehyde contents were determined by colorimetric reactions followed spectrofotometrically (Bates et al., 1973; Du and Bramlage, 1992).

\subsection{Description of the second experiment}

The second study site was located at Lavello (Southern Italy, Basilicata region - $\mathrm{N} 41^{\circ} 03^{\prime}$, E $15^{\circ} 42^{\prime}$ ), a semi-arid area with average annual rainfall of $670 \mathrm{~mm}$ concentrated in the October-February period and monthly average temperatures ranging from 5.7 to $24.1^{\circ} \mathrm{C}$. This experimental site is characterised by intense and frequent dry conditions as one may observe from the probability density function of the relative saturation of soil, $s$ (given by the ratio between the soil water content, $\theta$, and the soil porosity, $n$ ), obtained via numerical simulation (Fig. 1). Numerical analyses were performed adopting the simulation scheme for soil water balance proposed by Rodríguez-Iturbe et al. (1999) adopting recorded rainfall and evapotranspiration data over a period of 40 years in order to account for the seasonal fluctuations of the climatic forcing. The distribution refers to the study area adopted in the field experiment and looks like a gamma distribution (e.g., Isham et al., 2005). The probability distribution displays dry conditions $(s \leq 0.3-0.4)$ with a high frequency and also an elevated dispersion mainly due to the seasonal fluctuations of rainfall and temperatures.

In this experiment, the relationships between canopy and roots were examined on own-rooted olive plants, cv. Coratina, planted in 1992 at distances of $6 \times 3 \mathrm{~m}$, regularly pruned and monitored throughout a period of seven years after planting. During this period, irrigation was suspended in part of the plot (the plants were watered only by rain), whereas the rest was irrigated using a localized system (microjets discharging $80 \mathrm{~L} \mathrm{~h}^{-1}$ over a $1 \mathrm{~m}$-radius). The soil was a sandy loam (53.3\% sand, $29.0 \%$ silt and $17.7 \%$ clay).

In the first year, roots were extracted from the whole volume of soil explored, while in the following years, the total soil volume explored by the roots was divided into $30 \mathrm{~cm}$ layers using the trench method (Böhm, 1979). Roots were separated from the soil using sieves of 2 and $5 \mathrm{~mm}$ mesh. The dry weight of each plant part (fruits, leaves, shoots, trunk, stump and roots) was measured after drying plant tissues at $80^{\circ} \mathrm{C}$ for $24 \mathrm{~h}$.

\section{Tolerance strategies against drought stress}

\subsection{Gas exchange and fluorescence measurements}

Morphological and anatomical features such as microphyllia, the thick leaf cuticle with large amounts of waxy substances, the hairiness of the leaf abaxial surface and the high specific weight of the leaves (sclerophylly) are means developed by olive plants to reduce water loss. Transpiration rates in olive are higher than in most other fruit tree species under both well-watered and drought conditions, and the various tissues

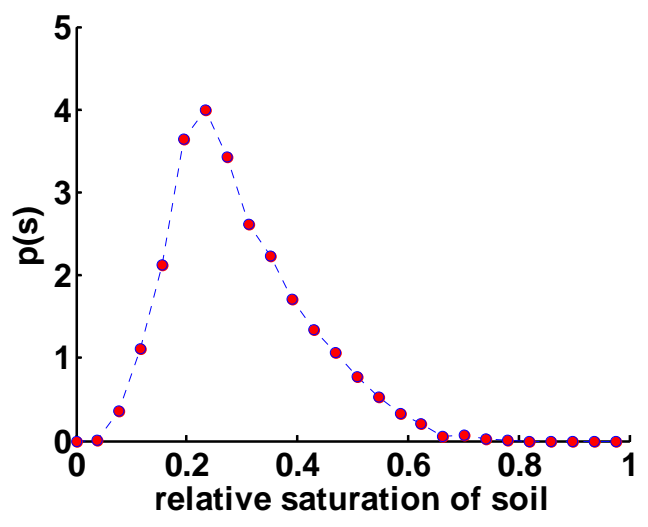

Fig. 1. Probability density function of the relative saturation of soil obtained simulating the soil water balance over 40 years in Lavello, a Mediterranean area of Southern Italy (soil characteristics are the following: porosity $n=0.44$, field capacity $\theta_{c}=0.38$, saturated conductivity $K_{S}=8.6 \mathrm{~cm} /$ day).

can withstand very negative values of water potential (Xiloyannis et al., 2003).

The first experiment, carried out on two-year old plants, was aimed to investigate on the effects of drought stress on plant transpiration and photosynthesis. The measured relative saturation of soil in drought-stressed plants during the first experiment is described in Fig. 2a, where the drying phase lasted 22 days and there after soil water content was kept fairly constant for one month. During this experiment, the transpiration was monitored and showed an interesting behaviour when compared with the trend of relative soil saturation (Fig. 2b). In particular, transpiration occured at the maximum rate as long as soil moisture was sufficient to permit the normal course of plant physiological processes but, when relative soil saturation became lower than 0.35 , the transpiration was inhibited and it decreased almost linearly with the soil water content.

In normal conditions, plant transpiration can be computed as a function of relative soil saturation following the expression (e.g., Laio et al., 2001)

$E(s)=\left\{\begin{array}{cc}E_{\max } \frac{s-s_{w}}{s^{*}-s_{w}} & s_{w} \leq s \leq s^{*} \\ E_{\max } & s^{*} \leq s \leq 1\end{array}\right.$

where $E_{\max }$ is the maximum rate of transpiration that during the experiment was fairly constant (see VPD - Vapor Pressure Deficit in Fig. 2a), $s^{*}$ is the relative soil saturation at the initial stomata closure and $s_{w}$ correspond to the relative saturation of soil at the wilting point. Nevertheless, another relevant aspect for a correct description of the soil-plant continuum is that transpiration was inhibited during the rewatering phase even if the soil saturation was above $s^{*}$ (Fig. 2b). This was likely due to the potential damages induced by the prolonged water-stress in plants. In this case, the olive tree was able to recover its functionality within one month, but during this period transpiration was significantly reduced and 

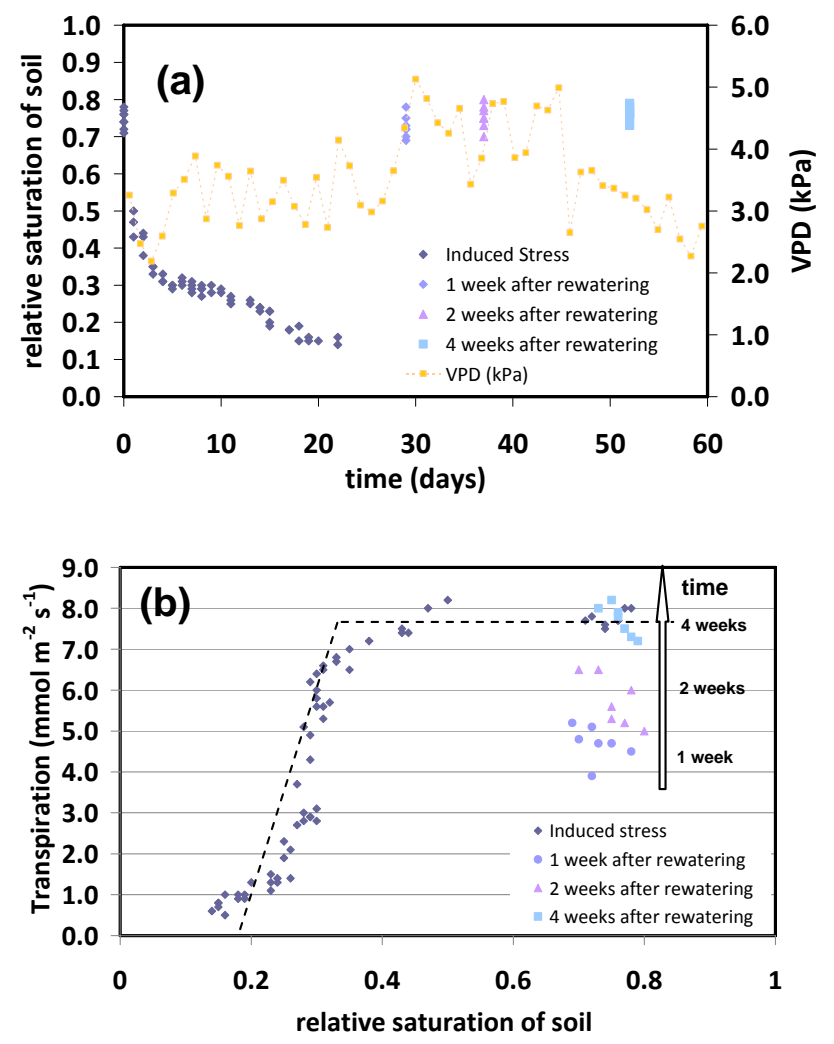

Fig. 2. (a) Measurements of soil saturation during an experiment where olive plants were driven toward drought-stressed conditions and watered afterwards. (b) Measured transpiration as a function of the relative saturation of soil. The dashed line describes the loss function introduced by Laio et al. (2001).

Eq. (1) should be applied accounting for this reduction in the actual transpiration rate. This mechanism would become particularly interesting under natural condition where soil watering (rainfall) is a stochastic process in time. The plant, according to the results given above, may use more parsimoniously the soil water resource in order to face prolonged periods of drought. Of course this assumption needs to be confirmed designing a dedicated experiment where the rewatering occurs randomly in time.

Reduction of soil water content from a relative soil saturation of 0.7 to approximately 0.4 induced in olive plants a slight drop in pre-dawn leaf water potential $\left(\Psi_{w}\right)$ (from -0.5 to $-0.9 \mathrm{MPa}$ ). At this value, daily transpiration per unit of leaf area is reduced by about 55\% while photosynthesis decreases approximately of $30 \%$ if compared to wellirrigated plants (Fig. 3). However, unlike in other species, leaves continue to function even at $\Psi_{w}$ of $-6.0 \mathrm{MPa}$. In dry condition, olive leaves can use for transpiration about $60 \%$ of their water reserves without irreversible damage. This water contributes to sustain the demands of transpiration as stress increases, up to extreme values of the leaf water potential of $-7.0 \mathrm{MPa}$, when relative water content of the plant reaches

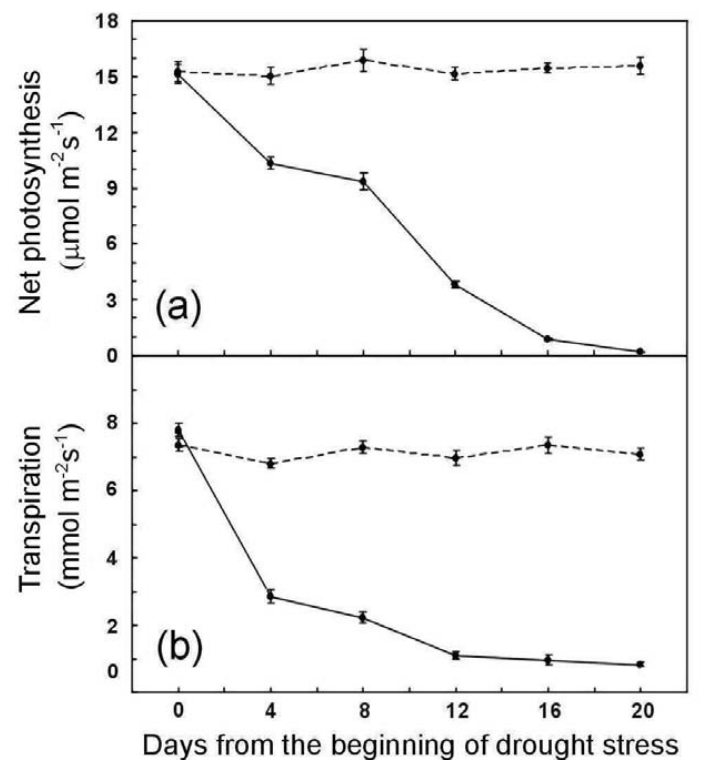

Fig. 3. Trends of net photosynthesis (a) and transpiration (b) in drought-stressed (continuous lines) and irrigated (dashed lines) during a drought stress period. Each value represents the mean of three measurements $( \pm \mathrm{SE})$ from three plants having a similar value of pre-dawn leaf water potential. The mean values of predawn leaf water potential for drought-stressed plants are the following: 0 days $=-0.4 \mathrm{MPa}, 4$ days $=-1.0 \mathrm{MPa}, 8$ days $=-1.7 \mathrm{MPa}, 12$ days $=-3.1 \mathrm{MPa}, 16$ days $=-4.2 \mathrm{MPa}$ and 20 days $=-5.8 \mathrm{MPa}$.

$40 \%$. This value is considerable if compared to that of other fruit species such as kiwifruit, which uses for transpiration a limited amount of water (about 9\%) from its reserves under conditions of severe water deficit (Nuzzo et al., 1997).

During the first days of recovery following a drought phase, olive plants recover only partially leaf water potential but recover completely the maximum photosynthetic efficiency calculated as $F_{v} / F_{m}$, where $F_{v}$ is the variable fluorescence and $F_{m}$ maximal fluorescence measured on dark-adapted leaves by means of a leaf chamber fluorometer (Table 1). The analysis of fluorescence relaxation curves allowed to calculate the value of slowly relaxing nonphotochemical quenching $\left(\mathrm{NPQ}_{S}\right)$, which indicates a damage of photosynthetic reaction centres and thus measures the degree photoinhibition, the damage to the light-harvesting reactions of the photosynthetic apparatus caused by excess light energy trapped by chloroplasts. Photoinhibition is thus the cause of the non-stomatal limitation to photosynthesis. Results show that $\mathrm{NPQ}_{s}$ increased with increasing drought stress and then recovered completely at the end of rewatering whereas in well-irrigated control plants it remained stable during the whole experimental period (Table 2). This suggests that olive plants have a strong mechanism for photosystem II repair after long-term photoinhibition and drought stress. The transpiration rates in the first two weeks of the rewatering period were much lower than the values of well- 
Table 1. Trends of pre-dawn leaf water potential $\left(\Psi_{w}\right)$, net photosynthetic rate $(A)$ and maximum efficiency of photosystem II $\left(F_{v} / F_{m}\right)$ during the rewatering of severely stressed plants. Each value represents the mean of three measurements $( \pm$ SE) from three plants having a similar value of pre-dawn leaf water potential.

\begin{tabular}{cccc}
\hline $\begin{array}{c}\text { Days of rewatering } \\
(\mathrm{MPa})\end{array}$ & $\begin{array}{c}\Psi_{w} \\
\left(\mu \mathrm{mol} \mathrm{CO}_{2} \mathrm{~m}^{-2} \mathrm{~s}^{-1}\right)\end{array}$ & $A$ & $F_{v} / F_{m}$ \\
\hline 1 & -6.50 & $6.6 \pm 0.78$ & $0.643 \pm 0.081$ \\
2 & -1.30 & $7.8 \pm 1.12$ & $0.742 \pm 0.043$ \\
3 & -0.85 & $9.4 \pm 1.01$ & $0.772 \pm 0.063$ \\
4 & -0.80 & $11.1 \pm 1.21$ & $0.789 \pm 0.045$ \\
5 & -0.80 & $9.7 \pm 1.10$ & $0.798 \pm 0.054$ \\
Control & -0.45 & $22.1 \pm 0.95$ & $0.816 \pm 0.036$ \\
\hline
\end{tabular}

watered plants and their complete recovery occurs after four weeks of rewatering (Fig. 2b). A similar inhibition during the first days of rewatering was also observed for photosynthetic rates (Table 1). It is important to note that in olive plants the extent of gas exchange inhibition is related to the level of drought stress previously experienced by plants (Angelopoulous et al., 1996). These persisting deficits in leaf gas exchange are not due to the non-recovery of cell turgor but to other factors probably involving the hormonal and biochemical balance, the efficiency of the conducting system and the water absorption capacity of roots.

\subsection{Osmotic adjustment and cell wall properties}

Another important mechanism adopted by the olive tree to face water deficit is osmotic adjustment. This physiological process is due to the accumulation of osmotically active compounds (osmolytes such as: carbohydrates, some aminoacids and derivates, organic and inorganic acids, cations and anions) in plant cells, measured by the variation in osmotic potential $\left(\Delta \Psi_{\pi}\right)$. A higher concentration of osmolytes facilitates water diffusion in cells and maintains the turgor of plant tissues. The osmotic adjustment may depend on either active synthesis and accumulation of osmolytes within cells (active osmotic adjustment) or loss of water from plant cells, with the consequent increase in osmolyte concentration (passive osmotic adjustment).

In the first experiment, leaf osmotic potential $\left(\Psi_{\pi}\right)$ at full turgor decreased from $-2.06 \pm 0.01 \mathrm{MPa}$ to $-2.81 \pm 0.03 \mathrm{MPa}$ in olive plants subjected to a severe drought stress. Under this condition, the olive tree uses active and passive $\Delta \Psi_{\pi}$ not only in leaves, but also in roots increasing its ability to extract water from dry soil. In fact, an active $\Delta \Psi_{\pi}$ of $1.42 \mathrm{MPa}$ was observed in roots having a 1-4 mm-diameter. This physiological response reduces osmotic potential $\left(\Psi_{\pi}\right)$, so allowing a favourable soil-plant water gradient which enables plants to extract water from soil at low values of soil water potential and to maintain gas exchange, growth and productivity (Xiloyannis et al., 1988). The passive concentration of solutes within cells was found to be the most important mechanism to maintain cellular turgor. In fact, the contribution of passive $\Delta \Psi_{\pi}$ represents approximately $60 \%$ of the total osmotic adjustment, while the remaining $40 \%$ is due to active $\Delta \Psi_{\pi}$ (Table 3 ).

The ex-novo synthesis of osmolytes takes place in both leaves and roots of the olive tree and regards mainly carbohydrates and the aminoacid proline (Cataldi et al., 2000). Extracts of leaves and roots of well-watered olive revealed that the most predominant carbohydrates are mannitol and glucose, which account for more than $80 \%$ of the total soluble carbohydrates. At a $\Psi_{w}$ of $-6.0 \mathrm{MPa}$, in olive tissues mannitol increased of about $97 \%$ and it was about $15 \%$ more concentrated than glucose. Moreover, it was found that the contribution to total $\Delta \Psi_{\pi}$ in severe-stressed plants made by glucose and mannitol combined was about $-0.32 \mathrm{MPa}$ and an increase in malic acid concentration also occurred. The levels of glucose, sucrose and stachyose decreased in thin roots at all the levels of water deficit, whereas medium roots exhibited no differences in the levels of these carbohydrates. Inorganic cations in olive leaves remained almost unchanged during the period of drought stress, except for the amount of $\mathrm{Ca}^{2+}$ which increased of $25 \%$ in water-stressed plants. The amount of organic acids such as malate increased both in leaves and roots during the dry period, whereas citrate and oxalate decreased. In olive plants, a rapid increase of proline at $\Psi_{w}$ lower than $-3.0 \mathrm{MPa}$ was observed both in leaves and roots. In particular, proline level in olive leaves reached $1.59 \pm 0.03 \mu \mathrm{mol} \mathrm{mg}^{-1} \mathrm{DW}$ at severe water deficit, so giving a considerable contribute to the decrease in $\Psi_{\pi}$. The results support the hypothesis that the observed decreases in $\Psi_{\pi}$ and the consequent osmotic adjustment in leaves and roots of drought-stressed plants were mainly due to the accumulation of mannitol, $\mathrm{Ca}^{2+}$, malate and proline within cells. Finally, the maintenance of negative values of $\Delta \Psi_{\pi}$ also during the rewatering phase suggests that this can be a strategy for this species to withstand other possible periods characterized by water deficit.

Another aspect investigated during this experiment was the elasticity of plant tissues. This parameter depends on 
Table 2. Slowly relaxing non-photochemical quenching $\left(\mathrm{NPQ}_{S}\right)$ in leaves of drought-stressed and control olive plants during the experimental period. Each value represents the mean of three measurements $( \pm S E)$ from three plants having a similar value of pre-dawn leaf water potential $\left(\Psi_{w}\right)$.

\begin{tabular}{lccc}
\hline & \multicolumn{3}{c}{$\mathrm{NPQ}_{S}$} \\
\hline & $\begin{array}{c}\text { Beginning of drought } \\
\left(\Psi_{w}=-0.45 \mathrm{MPa}\right)\end{array}$ & $\begin{array}{c}\text { Maximum level of drought } \\
\left(\Psi_{w}=-6.50 \mathrm{MPa}\right)\end{array}$ & $\begin{array}{c}\text { End of rewatering } \\
\left(\Psi_{w}=-0.45 \mathrm{MPa}\right)\end{array}$ \\
\hline Drought-stressed & $0.42 \pm 0.02$ & $0.58 \pm 0.04$ & $0.45 \pm 0.08$ \\
Control $\left(\Psi_{w}=-0.45 \mathrm{MPa}\right)$ & $0.41 \pm 0.02$ & $0.42 \pm 0.02$ & $0.42 \pm 0.03$ \\
\hline
\end{tabular}

Table 3. Passive, active and total osmotic adjustment measured predawn in leaves of drought-stressed olive plants. Each value represents the mean of three measurements $( \pm S E)$ from three plants having a similar value of pre-dawn leaf water potential $\left(\Psi_{w}\right)$.

\begin{tabular}{cccc}
\hline \multirow{2}{*}{$\Psi_{w}(\mathrm{MPa})$} & \multicolumn{3}{c}{ Osmotic adjustment $(\mathrm{MPa})$} \\
& Passive & Active & Total \\
\hline-1.7 & $0.21 \pm 0.03$ & $0.13 \pm 0.02$ & $0.34 \pm 0.05$ \\
-3.3 & $0.56 \pm 0.08$ & $0.30 \pm 0.05$ & $0.86 \pm 0.10$ \\
-5.4 & $1.38 \pm 0.12$ & $1.04 \pm 0.13$ & $2.42 \pm 0.28$ \\
\hline
\end{tabular}

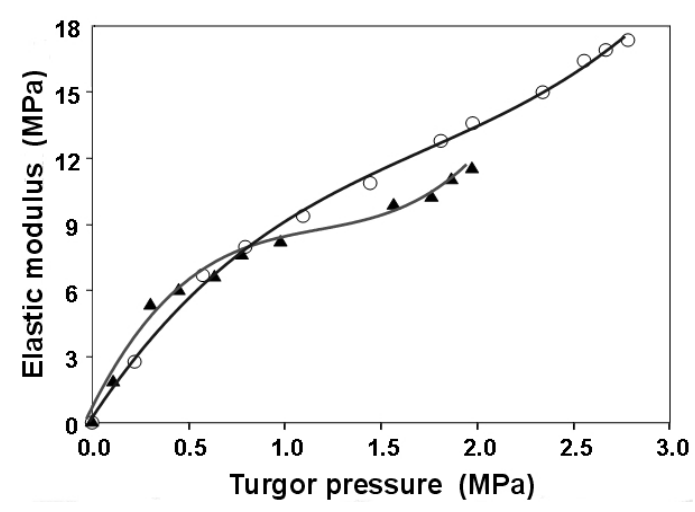

Fig. 4. Relationship between the bulk elastic modulus and turgor potential shown by representative leaves for well-watered $(\boldsymbol{\Lambda})$ and drought-stressed (pre-dawn leaf water potential=-5.2 MPa) $(\bigcirc)$ olive plants.

the composition and structure of the cell wall, the rigid outermost cell layer found in plant cells. An increase in elastic modulus $(\varepsilon)$ is expected when cell walls become more rigid or thicker, and higher values of elastic modulus produces a faster turgor loss of cells for a given percentage of dehydration.

As drought-stress increases, the maximum elastic modulus in olive leaf tissues rose from $11.6 \pm 0.95 \mathrm{MPa}$ to 18.6 $\pm 0.61 \mathrm{MPa}$ (Fig. 4). This suggests that a droughtstressed olive tree activates metabolic processes to produce substances that increase cell tissue rigidity, likely by regulating some enzymes involved in lignin biosynthesis such as peroxidases (Sofo et al., 2004a). High values of elastic modulus, together with low values of $\Psi_{\pi}$ can be responsible for the observed high gradients of water potential between leaves and soil and thus can facilitate water extraction from the soil.

\subsection{Regulation of antioxidant enzymes and markers of ox- idative stress}

Drought stress is often associated with increased cellular levels of activated oxygen species (AOS), such as superoxide anion $\left(\mathrm{O}_{2}^{-}\right)$, hydrogen peroxide $\left(\mathrm{H}_{2} \mathrm{O}_{2}\right)$, hydroxyl radical $\left(\mathrm{HO}^{\cdot}\right)$ and singlet oxygen $\left({ }^{1} \mathrm{O}_{2}\right)$. AOS are very reactive chemical compounds able to oxidize and damage cells and for this reason plants can increase the activity of antioxidant enzymes (such as: ascorbate peroxidase, catalase, superoxide dismutase, peroxidase, and polyphenol oxidase) to remove them (see Smirnoff, 1993).

The olive tree is able to up-regulate the enzymatic antioxidant system as plants enter water deficit conditions (Table 4). This response protects cellular apparatus and limits cellular damage caused by AOS. In fact, the activities of ascorbate peroxidase (APX) and catalase (CAT) showed a significant increase in leaves of drought-stressed plants, reaching values of $13.77 \pm 0.55$ units $\mathrm{mg}^{-1} \mathrm{DW}$ and $11.78 \pm 0.18$ units $\mathrm{mg}^{-1}$ DW, respectively. Moreover, the activities of superoxide dismutase (SOD) and peroxidase (POD) increased both in leaves and roots. Superoxide dismutase enzyme causes the transformation of toxic superoxide anions to water and oxigen whereas peroxidase is involved in lignin biosynthesis and thus participates in the modulation of cell wall properties. For this reason, the observed increase in peroxidase activity could reflect the changed mechanical properties of the cell wall, which in turn, can be correlated with drought adaptation. In contrast, polyphenol oxidase (PPO) activity decreased during the progression of stress in all the tissues studied. Results suggest that drought stress may improve the antioxidant action of phenols by inhibiting polyphenol oxidase and consequently by maintaining the phenol compounds pool in their active reduced state. 
Table 4. Activities of superoxide dismutase (SOD), ascorbate peroxidase (APX), catalase (CAT), guaiacol peroxidase (POD), polyphenol oxidase (PPO) and lipoxygenase (LOX) in leaves and roots of drought-stressed and well-watered control olive plants. Each value represents the mean of three measurements $( \pm \mathrm{SE})$ from three plants having a similar value of pre-dawn leaf water potential $\left(\Psi_{w}\right)$. Stars refer to differences between well-watered and drought-stressed plants at $P=0.05$.

\begin{tabular}{|c|c|c|c|c|c|c|c|}
\hline \multicolumn{2}{|c|}{ Pre-dawn leaf water potential (MPa) } & \multicolumn{6}{|c|}{ Enzyme activity (units $\mathrm{mg}^{-1}$ dry weight) } \\
\hline & & SOD & APX & CAT & POD & PPO & LOX \\
\hline \multirow{4}{*}{ Leaves } & -0.4 (control) & $15.21 \pm 0.82$ & $3.88 \pm 0.20$ & $4.52 \pm 0.18$ & $29.21 \pm 1.24$ & $33.49 \pm 0.87$ & $149.93 \pm 7.35$ \\
\hline & -1.6 & $30.73 \pm 0.89 *$ & $7.36 \pm 0.07 *$ & $6.81 \pm 0.05^{*}$ & $39.06 \pm 1.97 *$ & $26.55 \pm 0.85 *$ & $240.10 \pm 9.12 *$ \\
\hline & -4.3 & $31.69 \pm 1.90 *$ & $12.11 \pm 0.26^{*}$ & $11.44 \pm 0.74 *$ & $48.17 \pm 2.01 *$ & $24.13 \pm 1.34 *$ & $461.35 \pm 28.20 *$ \\
\hline & -5.7 & $25.17 \pm 1.06^{*}$ & $13.77 \pm 0.55^{*}$ & $11.78 \pm 0.18^{*}$ & $40.66 \pm 0.73 *$ & $20.36 \pm 0.91 *$ & $492.43 \pm 34.29 *$ \\
\hline \multirow{4}{*}{ Roots } & -0.4 (control) & $7.99 \pm 0.20$ & $0.36 \pm 0.01$ & $2.08 \pm 0.02$ & $23.88 \pm 0.34$ & $38.19 \pm 0.99$ & $54.45 \pm 2.57$ \\
\hline & -1.6 & $11.20 \pm 0.28 *$ & $0.42 \pm 0.01 *$ & $3.10 \pm 0.07 *$ & $39.05 \pm 1.56^{*}$ & $35.63 \pm 0.74 *$ & $59.27 \pm 1.20 *$ \\
\hline & -4.3 & $15.94 \pm 0.59 *$ & $0.56 \pm 0.02 *$ & $2.74 \pm 0.10 *$ & $47.77 \pm 2.11 *$ & $21.43 \pm 0.43 *$ & $55.21 \pm 2.54 *$ \\
\hline & -5.7 & $17.19 \pm 0.49^{*}$ & $0.51 \pm 0.02 *$ & $2.58 \pm 0.07 *$ & $44.56 \pm 1.27 *$ & $19.05 \pm 0.33 *$ & $50.79 \pm 1.42 *$ \\
\hline
\end{tabular}

Significant increases of lipoxygenase (LOX) activity and malondialdehyde (MDA) content, two markers of oxidative stress, were also observed during the progressive increment of drought stress in both leaf and root tissues of olive plants. The observed increases in malondialdehyde levels and lipoxygenase activity suggest that the water deficit is associated with the oxidation of membrane lipids caused by activated oxygen species and with the damage of photosynthetic apparatus.

During a rewatering treatment following a drought period, the activities of antioxidant enzymes and the levels of malondialdehyde decreased in both leaves and roots, while polyphenol oxidase activity increased.

\subsection{Growth parameters}

The second experiment, carried out in field, highlighted the different growth rates of olive tree's organs between drought-stressed and well-watered plants. It was found that non-irrigated olive plants have higher values of root dry weight/leaf area ratio, volume of explored soil/leaf area ratio, and therefore have greater water availability per unit of leaf area (Celano et al., 1999; Palese et al., 2000).

The results showed that lower soil water availability determines a greater growth reduction in the above-ground organs than in the under-ground organs (roots and stump) (Fig. 5). At the seventh year after planting, the under/above-ground ratio in non-irrigated trees was 0.81 in comparison to 0.72 in irrigated ones. This reduction involved all the epigean organs but was particularly marked in leaf dry weight which at the seventh year was $47 \%$ lower in non-irrigated plants. The greater decrease in canopy growth with respect to root growth in drought conditions is a mechanism which improves water availability per unit of leaf area, enabling plants to resist long water deficit periods while keeping the leaves

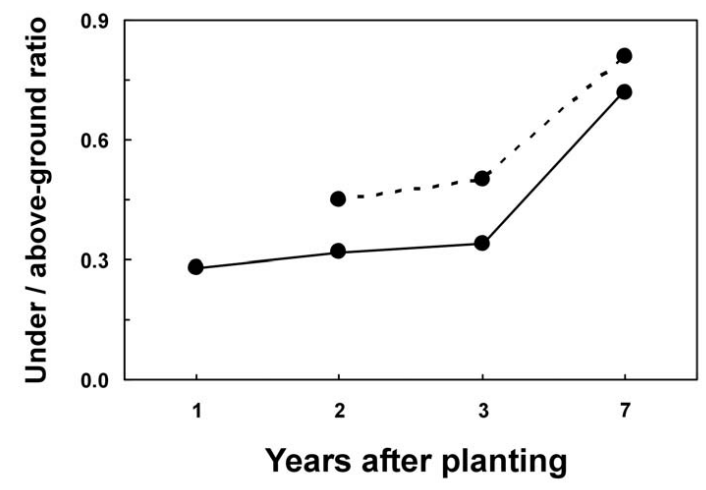

Fig. 5. Dry matter ratio between under- and above-ground tree parts in irrigated (solid line) and drought-stressed (dotted line) olive plants.

photosynthetically active. Root system of drought-stressed olive plants was deeper (up to $1.5 \mathrm{~m}$ ) if compared to wellwatered plants, while root density remains similar in the two conditions (about $0.020 \mathrm{~m} \mathrm{~m}^{-3}$ of soil). This data demonstrate the positive effect of water availability on the growth of both canopy and roots, and the ability of the olive tree to explore the deeper soil layers when grown under water deficit.

\section{Conclusions and final remarks}

Experimental results provide a deep overview of the different mechanisms developed by the olive tree in order to deal with water limited conditions. A summary of drought stress effects on this species is given in Fig. 6, where the inhibition of physiological processes due to the decrease in pre-dawn leaf water potential $\left(\Psi_{w}\right)$ is depicted. 


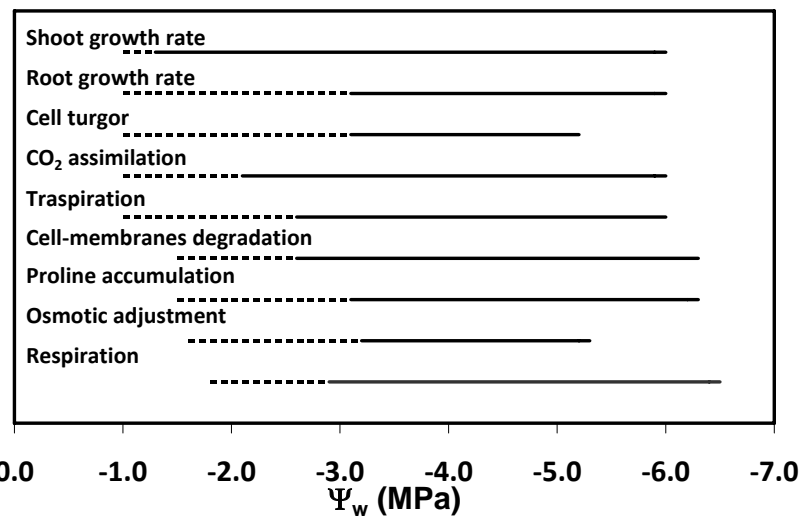

Fig. 6. Effects of the decrease in pre-dawn leaf water potential $\left(\Psi_{w}\right)$ on physiological processes of olive plants. Dashed lines describe the $\Psi_{w}$ intervals where physiological processes are partially inhibited or induced, while continuous lines describe the intervals where those processes are strongly affected by drought stress.

The first effect of the decrease in $\Psi_{w}$ is a reduction in cell turgor and gas exchange. If compared to a mean response of a plant to drought stress (Hsiao, 1973), the olive tree is able to maintain cell turgor at much lower $\Psi_{w}$ values. This is likely due to the stiffness of cell walls related to the high values of elastic modulus, that increase with drought intensity, and to the reduced water losses from cells. The inhibition of photosynthesis begins very soon and is accompanied by a decrease in transpiration. This suggests that, in olive plants subjected to water deficit, photochemical processes are affected not only by photoinhibition and photo-oxidation but stomatal factors are also involved. Moreover, shoot growth rate seems to be more sensitive to the decrease in $\Psi_{w}$ if compared to root growth rate and this can be the cause of the higher root/shoot ratio of drought-stressed plants (Fig. 5). At values of $\Psi_{w}$ below $-1.5 \mathrm{MPa}$, when gas exchange and growth rates are inhibited, the degradation of cell membranes due to lipid peroxidation takes place.

The regulation of stomata closure is one of the first effects of drought stress on olive tree's physiology and it is gradual with the decrease of $\Psi_{w}$. The stomata closure starts to be more relevant for values of $\Psi_{w}$ below $-2.5 \mathrm{MPa}$ and at this point it is followed by a strong decrease in cell turgor (Fig. 6). For values of $\Psi_{w}$ below $-3.2 \mathrm{MPa}$, the osmotic adjustment due the accumulation of proline, carbohydrates and other osmolytes is completely active and allows the conservation of water in olive tissues. Soon after, respiration is partially reduced by disturbances in cell metabolism.

The patterns described in Fig. 6 and the comparisons with other Mediterranean plant species (Lo Gullo and Salleo, 1988) give evidence for a high degree of tolerance of the olive tree against water deficit and a concerted and gradual series of adaptation mechanisms against this abiotic stress. The analyses here discussed may be useful to better understand the physiological mechanisms adopted by a model plant for water stress tolerance in a Mediterranean ecosystem.

Acknowledgements. S. M. acknowledges the support of the CARICAL foundation for his research activities. This research was financed by the projects BRIMET (P.O.N. - Metodologie e sistemi integrati per la valorizzazione di prodotti ortofrutticoli di particolare interesse degli areali di Brindisi e Metaponto) and OLIVERO (European Union Research Project QLK5 CT-2002-01841).

Edited by: V. Iacobellis

\section{References}

Angelopoulos, K., Dichio, B., and Xiloyannis, C.: Inhibition of photosynthesis in olive trees (Olea europaea L.) during water stress and rewatering, J. Exp. Bot., 47(301), 1093-1100, 1996.

Bacelar, E. A., Santos, D. L., Moutinho-Pereira, J. M., Lopes, J. I., Gonçalves, B. C., Ferreira, T. C., and Correia, C. M.: Physiological behaviour, oxidative damage and antioxidative protection of olive trees grown under different irrigation regimes, Plant Soil, 292, 1-12, 2007.

Bates, L. S., Waldren, R. P., and Teare, I. K.: Rapid determination of free proline for water stress studies, Plant Soil, 39,: 205-208, 1973.

Bohm, W.: Methods of studying root systems, in: Ecological Studies, Vol. 33, edited by: Bellings, W. D., Galleg, F., Lange, O. L., and Olson, J. S., Springer Verlag New York, 116-117, 1979.

Bolle, H. J.: Mediterranean Climate: Variability and Trends, Springer, New York, 320 pp., 2003.

Cataldi, T. R., Margiotta, G., Iasi, L., Dichio, B., Xiloyannis, C., and Bufo, S. A.: Determination of sugar compounds in olive plant extracts by anion-exchange chromatography with pulsed amperometric detection, Anal. Chem., 72, 3902-3907, 2000.

Celano, G., Dichio, B., Montanaro, G., Nuzzo, V., Palese, A. M., and Xiloyannis, C.: Distribution of dry matter and amount of mineral elements in irrigated and non-irrigated olive trees, Acta Horticulturae, 474, 381-384, 1999.

Chartzoulakis, K., Patakas, A., and Bosabalidis, A. M.: Changes in water relations, photosynthesis and leaf anatomy induced by intermittent drought in two olive cultivars, Environ. Exp. Bot., 42, 113-120, 1999.

Connor, D. J. and Fereres, E.: The physiology of adaptation and yield expression in olive, Hortic. Rev., 31, 155-229, 2005.

Dichio, B., Xiloyannis, C., Sofo, A., and Montanaro, G.: Osmotic adjustment in leaves and roots of olive tree (Olea europaea L.) during drought stress and rewatering, Tree Physiol., 26, 179-185, 2006

Du, D. and Bramlage, W. J.: Modified thiobarbituric acid assay for measuring lipid oxidation in sugar-rich plant tissue extracts, J. Agric. Food Chem., 40, 1566-1570, 1992.

Favia, F. and Celano, G.: I sistemi olivicoli in terreni collinari e montani: Basilicata e Campania, in: Il futuro dei sistemi olivicoli in aree marginali: aspetti socio-economici, conservazione delle risorse naturali e produzioni di qualità, L'Aquilone, 123158, 2005.

Fernández, J. E., Moreno, F., Girón, I. F., and Blázquez, O. M.: Stomatal control of water use in olive tree leaves, Plant Soil, 190, 179-192, 1997. 
Fiorentino, M., Carriero, D., Iacobellis, V., Manfreda, S., and Portoghese, I.: MEDCLUB - starting line and first activities, in: Predictions in Ungauged Basins: Promises and Progress, edited by: Sivapalan, M., Wagener, T., Uhlenbrook, S., Zehe, E., Lakshmi, V., Liang, X., Tachikawa, Y., and Kumar, P., IAHS Publ., 303, 2006.

Girma, F. S., Krieg, D. R.: Osmotic adjustment in Sorghum. I. Mechanisms of diurnal osmotic potential changes, Plant Physiol, 99, 577-582, 1992.

Hsiao, T. C.: Plant responses to water stress, Ann. Rev. Plant Physiol., 24, 519-570, 1973.

Isham, V., Cox, D. R., Rodríguez-Iturbe, I., Porporato, A., and Manfreda, S.: Representation of Space-Time Variability of Soil Moisture, Proceedings of the Royal Society A: Mathematical, Phys. Eng. Sci., 461, 4035-4055, doi:10.1098/rspa.2005.1568, 2005.

Laio, F., Porporato, A., Ridolfi, L., and Rodríguez-Iturbe, I.: Plants in water controlled ecosystems: Active role in hydrological processes and response to water stress, II. Probabilistic soil moisture dynamics, Adv. Water Res., 24, 707-723, 2001.

Lo Gullo, M. A. and Salleo, S.: Different strategies of drought resistance in three Mediterranean schlerophyllous trees growing in the same environmental conditions, New Phytol., 108, 267-276, 1988.

Loumou, A. and Giourga, C.: Olive groves: The life and identity of the Mediterranean, Agricu. Hum. Values, 20, 87-95, 2003.

Moreno, F., Fernández, J. E., Clothier, B. E., and Green, S. R.: Transpiration and root water uptake by olive trees, Plant Soil, 184, 85-96, 1996.

Nogués, S. and Baker, N. R.: Effects of drought on photosynthesis in Mediterranean plants grown under enhanced UV-B radiation, J. Exp., 51, 1309-1317, 2000.

Nuzzo, V., Dichio, B., Xiloyannis, C., Piccotino, D., and Massai, R.: Contribution to transpiration of different tissues of kiwifruit vines from their water reserves, Acta Horticulturae, 444, 329334, 1997.

Palese, A. M., Nuzzo, V., Dichio, B., Celano, G., Romano, M., and Xiloyannis, C.: The influence of soil water content on root density in young olive trees, Acta Horticulturae, 537, 329-336, 2000 .
Rodríguez-Iturbe, I., Porporato, A., Ridolfi, L., Isham, V., and Cox, D. R.: Probabilistic modelling of water balance at a point: The role of climate, soil and vegetation, Proceedings of the Royal Society A: Mathematical, Phys. Eng. Sci., 455, 3789-3805, 1999.

Smirnoff, N.: The role of active oxygen in the response to water deficit and desiccation, New Phytol., 125, 27-58, 1993.

Sofo, A., Dichio, B., Xiloyannis, C., and Masia, A.: Effects of different irradiance levels on some antioxidant enzymes and on malondialdehyde content during rewatering in olive tree, Plant Sci., 166, 293-302, 2004a.

Sofo, A., Dichio, B., Xiloyannis, C., and Masia, A.: Lipoxygenase activity and proline accumulation in leaves and roots of olive tree in response to drought stress, Physiol. Plant., 121, 58-65, 2004b.

Teuling, A. J., Uijlenhoet, R., and Troch, P.A.: On bimodality in warm season soil moisture observations, Geophys. Res. Lett., 32(5), L05404, doi:10.1029/2005GL023223, 2005.

Tognetti, R., D’Andria, R., Morelli, G., Calandrelli, D., and Fragnito, F.: Irrigation effects on daily and seasonal variations of trunk sap flow and leaf water relations in olive trees, Plant Soil, 263, 249-264, 2004.

Tombesi, A., Proietti, P., and Nottiani, G.: Effect of water stress on photosynthesis, transpiration, stomatal resistance and carbohydrate level in olive tree, Olea, 17, 35-40, 1986.

Turner, N. C.: Techniques and experimental approaches for the measurement of plant water status, Plant Soil, 58, 339-366, 1981.

Tyree, M. T. and Jarvis, P. G.: Water in tissues and cells, in: Encyclopedia of Plant Physiology, edited by: Lange, O. L., Nobel, P. S., Osmond, C. B., and Ziegler, H., New Series, Vol. 12B, Springer-Verlag Berlin, 36-71, 1982.

Walters, R. G. and Horton, P.: Resolution of components of non-photochemical chlorophyll fluorescence quenching in barley leaves, Photosynth. Res., 27, 121-133, 1991.

Xiloyannis, C., Pezzarossa, B., Jorba, J., and Angelici, P.: Effects on soil water content on gas exchange in olive trees, Adv. Hortic. Sci., 2, 58-63, 1988.

Xiloyannis, C., Gucci, R., and Dichio, B.: Irrigazione, in: Olea: Trattato di Olivicoltura, edited by: Fiorino, P., ISBN 88-5064938-X, Il Sole 24 ORE Edagricole S.r.1., 365-389, 2003. 